\title{
Oral cancer incidence and survival rates in the Republic of Ireland, 1994-2009
}

\author{
Hala Ali $^{1^{*}}{ }^{\mathbb{D}}$, Sarah-Jo Sinnott ${ }^{2 \dagger}$, Paul Corcoran ${ }^{1,3 \dagger}$, Sandra Deady ${ }^{4}$, Linda Sharp ${ }^{5}$ and Zubair Kabir $^{1}$
}

\begin{abstract}
Background: Oral cancer is a significant public health problem world-wide and exerts high economic, social, psychological, and physical burdens on patients, their families, and on their primary care providers. We set out to describe the changing trends in incidence and survival rates of oral cancer in Ireland between 1994 and 2009.

Methods: National data on incident oral cancers [ICD 10 codes C01-C06] were obtained from the National Cancer Registry Ireland from 1994 to 2009. We estimated annual percentage change (APC) in oral cancer incidence during 1994-2009 using joinpoint regression software (version 4.2.0.2). The lifetime risk of oral cancer to age 79 was estimated using Irish incidence and population data from 2007 to 2009. Survival rates were also examined using Kaplan-Meier curves and Cox proportional hazard models to explore the influence of several demographic/lifestyle covariates with follow-up to end 2012.
\end{abstract}

Results: Data were obtained on 2,147 oral cancer incident cases. Men accounted for two-thirds of oral cancer cases $(n=1,430)$. Annual rates in men decreased significantly during 1994-2001 (APC $=-4.8 \%, 95 \% \mathrm{Cl}:-8.7$ to -0.7 ) and then increased moderately (APC $=2.3 \%, 95 \% \mathrm{Cl}:-0.9$ to 5.6). In contrast, annual incidence increased significantly in women throughout the study period (APC $=3.2 \%, 95 \%$ Cl: 1.9 to 4.6). There was an elevated risk of death among oral cancer patients who were: older than 60 years of age; smokers; unemployed or retired; those living in the most deprived areas; and those whose tumour was sited in the base of the tongue. Being married and diagnosed in more recent years were associated with reduced risk of death.

Conclusion: Oral cancer increased significantly in both sexes between 1999 and 2009 in Ireland. Our analyses demonstrate the influence of measured factors such as smoking, time of diagnosis and age on observed trends. Unmeasured factors such as alcohol use, HPV and dietary factors may also be contributing to increased trends. Several of these are modifiable risk factors which are crucial for informing public health policies, and thus more research is needed.

Keywords: Oral cancer, Incidence rate, Survival rate, Joinpoint regression, Time trend

\section{Background}

Oral cancer (OC) is a common cancer worldwide with an incidence of 300,000 cases in 2012, amounting for over $2 \%$ of the overall burden of cancer diagnoses globally [1]. It is the 7th leading cause of death from cancer in Europe [2]. In Ireland, about 233 oral cancer cases are diagnosed annually [3] and over the last 5 years (2011-2015 inclusive), an average number of 71 deaths from oral cancers have been recorded [4]. In recent years, these numbers

\footnotetext{
* Correspondence: hala.e.ali@gmail.com

${ }^{\dagger}$ Equal contributors

${ }^{1}$ Department of Epidemiology and Public Health, University College Cork, Cork, Ireland

Full list of author information is available at the end of the article
}

have been increasing [5]. A second issue of concern is the rising incidence of OC in women, which rose from $24 \%$ in 1994 to $32 \%$ in 2009 [5]. This is notable given that OC is traditionally more common in men [6].

Drinking alcohol alone is not an independent risk factor for OC but may have a mediating effect with smoking status $[7,8]$. Although alcohol consumption in Ireland has decreased over the past ten years, it remained the highest amongst OECD (Organisation for Economic Co-operation and Development) countries in 2012 with a consumption of $11.6 \mathrm{~L}$ of alcohol per adult per year, in comparison to the OECD average of 91 [9]. In 2010, Irish adults were still drinking more than twice 
the average amount of alcohol consumed per adult in 1960 [10]. This is accompanied by a culture of binge drinking which is not as problematic in other European countries [10].

However, significant improvements have been made in smoking behaviours which can be largely attributed to Ireland's innovation in implementing a smoking ban in public places in 2004. The prevalence of smoking was $19.5 \%$ in 2014 [11] compared to $29 \%$ in 2007 [12]. Nevertheless, smoking remains high among the 25-34 year age group $(27.3 \%)$ and in the lower socioeconomic groups [11]. A third important risk factor for certain types of OC is Human papillomavirus (HPV), transmitted through conventional and oral sexual contacts [13]. It is a common infection, $70-80 \%$ of Irish women will be infected with HPV at some stage in their life [14], although most will have the strength of immunity to clear the virus themselves [14]. In a study of 996 Irish women undergoing opportunistic cervical screening, overall HPV prevalence was $19.8 \%$ [15]. Given recent advances in the development and mass administration of HPV vaccines, this is now a modifiable risk factor with potential to reduce the incidence of these cancers [13].

Other potential risk factors commonly discussed are radiation, over exposure to ultraviolet sunlight (involved in lip cancer) [5], genetic predisposition [16] and socioeconomic status which has been found to be significantly linked with increased oral tumour risk in both low and high income countries [17]. Heavy metals like nickel and chromium and poor oral hygiene may also play roles in OC etiology [18].

\section{Rationale for the study}

Despite declines in mortality rates associated with $\mathrm{OC}$ in Ireland, recent evidence has pointed to an increase in incidence amongst certain demographic groups [19]. The changing profile of risk factors may have an explanatory role in this instance. Thus, in this study we aimed to first describe the changing trends of incidence of $\mathrm{OC}$ over the period 1994-2009. Second, we aimed to calculate the lifetime cumulative incidence risk of $\mathrm{OC}$ because such an estimate has not been undertaken in Ireland in recent years. Thirdly, we used relevant socio-demographic and clinical factors to explore survival rates in OC and to identify specific populations that may be at greater risk of mortality from oral cancers.

\section{Methods}

This study was approved by the Clinical Research Ethics Committee of the Cork Teaching Hospitals, Ireland.

\section{Data}

An anonymized dataset of oral cancer cases was obtained from the National Cancer Registry in Ireland
(NCRI). The NCRI records all cancers newly diagnosed in the population resident in Ireland. Completeness of registration is estimated to be at least $97 \%$ [20]. Based on the International Classification of Disease (ICD) tool from the World Health Organization oral cancer records were abstracted for cancers at the following sites; base of the tongue (C01), tongue (C02), gum (C03), floor of mouth (C04), palate (C05), and unspecified mouth (C06) for all patients aged over 15 years from 1994 up until the end of 2009. The NCRI follows cases by obtaining death certificates and linking these to registrations. Follow-up was complete to end 2012 [21].

\section{Covariates}

We included several covariates in our analyses based on highlighted risk factors for $\mathrm{OC}$ in the international literature [6]; sex, age-group, marital status, and year of diagnosis. Further covariates included smoking status at diagnosis (current smokers, never smokers, ex-smokers, unknown) [22], occupation status and local area socioeconomic status. Socioeconomic status was allocated to each record based on the electoral division (ED) of residence at the time of the patient's diagnosis. This areabased index was developed by the Small Area Health Research Unit at Trinity College Dublin and is described in Williams et al. 2003 [23]. Each ED was assigned a deprivation index, which used five census-based indicators from the 2002 Irish census (representing the midpoint of the period included in this analysis): unemployment, low social class, car ownership, rented accommodation and overcrowding [24]. The deprivation index ranged from 1 (least deprived) to 5 (most deprived).

For the statistical analysis we collapsed the deprivation index 1,2, 3 for least and 4, 5 for the most deprived score. We also included data on tumour site and tumour stage at diagnosis, which is a summary overall cancer stage based on the fifth edition of the American Joint Committee on Cancer (AJCC) TNM staging manual (1997) [25].

\section{Annual percent change (APC) 1994-2009}

Incidence rates for oral cancer of Irish individuals were calculated using the joinpoint regression program (version 4.2.0.2) [26], which models the natural logarithm of the rates, identifying years at which any given trend changes, connecting these years graphically by a series of straight line segments [27]. They are expressed as the annual percent (APC) over the reported trend period. Incidence rates were ageadjusted and reported per 100, 000 population using the direct approach to the European age-standard population. 


\section{Lifetime cumulative risk incidence}

Lifetime cumulative risks of $\mathrm{OC}$ incidence were calculated using denominator data for the population at risk from the Central Statistics Office Ireland from 2007 to 2009 and numerator data from the NCRI database was the number of diagnosed cases in 5 year age groups starting at 15 years up to $79(15-19,20-$ $24,25-29,30-34,35-39,40-44,45-49$, 50-54, 55-59, $60-64,65-69,70-74,75-79)$ for the years $2007-2009$ for both sexes.

Calculations were based on data aggregated over three years because oral cancer is relatively rare and the cumulative risk fluctuates from one year to the next.

\section{Survival analysis}

We assessed the probability of cancer-specific survival using Kaplan-Meier (KM) curves. To examine the influence of lifestyle and clinical risk factors on survival probability we used a Cox regression assuming proportional hazards. Multivariable Cox regression models included age, sex, smoking, marital status, deprivation level, occupation, cancer site and cancer stage.

Results were reported as hazard ratios (HR) with equivalent $95 \%$ confidence intervals (CI). All $p$-values were two tailed. The level of significance was set at 0.05. Data analysis was conducted using STATA (version 13.0).

\section{Results}

Population-based data from the NCRI indicated that 2,147 individuals aged $\geq 15$ years were diagnosed as new oral cancer cases between 1994 and 2009. Characteristics of the cases across three distinct periods (1994-1999, 2000-2004, 2005-2009) are presented below (Table 1). Of note, most cases occurred in men, in those aged over 60 years (median age of diagnosis was 63 years), in current smokers and in people who were most deprived.

\section{Annual percent change (APC)}

In females, oral cancer incidence rose significantly, by $3.2 \%$ per annum (95 \% CI: 1.9 to 4.6), during 19942009 (Table 2/Fig. 1). In contrast, an annual decline of -4.8 \% (95 \% CI: -8.7 to -0.7 ) was observed for male OC in the period between 1994-2001. In the most recent 8 year interval (2001-2009), the trend for men was judged to be stable i.e. a non-significant change at $2.3 \%$ (95 \% CI: -0.9 to 5.6) (Table 2/Fig. 1).

\section{Lifetime cumulative risk incidence}

The lifetime cumulative risk of incidence from $\mathrm{OC}$ to age 79 years for the period between 2007 and 2009 was estimated to be $0.7 \%$ and $0.5 \%$ for males and females respectively. In other words, on average, seven men out
Table 1 Characteristics of the 2,147 oral cancer patients diagnosed in 1994-2009

\begin{tabular}{|c|c|c|c|c|}
\hline Years & $\begin{array}{l}1994-1999 \\
(n=728)\end{array}$ & $\begin{array}{l}2000-2004 \\
(n=614)\end{array}$ & $\begin{array}{l}2005-2009 \\
(n=805)\end{array}$ & $\begin{array}{l}\text { Total } \\
(n=2147)\end{array}$ \\
\hline Women $n(\%)$ & $214(29.4)$ & $211(34.4)$ & $292(36.3)$ & $717(33.4)$ \\
\hline Men $n(\%)$ & $514(70.6)$ & $403(65.6)$ & $513(63.7)$ & $1430(66.6)$ \\
\hline \multicolumn{5}{|l|}{ Age (years) $n(\%)$} \\
\hline$<30$ & $6(0.8)$ & $7(1.1)$ & $19(2.4)$ & $32(1.5)$ \\
\hline $30-60$ & $224(33.5)$ & $262(42.7)$ & $309(38.4)$ & $815(37.9)$ \\
\hline$>60$ & $478(65.7)$ & $345(56.2)$ & $477(59.3)$ & $1300(60.6)$ \\
\hline Married $n(\%)$ & $353(48.4)$ & 317 (51.6) & $422(52.4)$ & $1092(50.9)$ \\
\hline Divorced n (\%) & $5(0.7)$ & $10(1.6)$ & $14(1.7)$ & $29(1.4)$ \\
\hline Single $n(\%)$ & $182(25.0)$ & $129(21.0)$ & $179(22.2)$ & $490(22.8)$ \\
\hline Other $n(\%)$ & $188(25.8)$ & $158(25.7)$ & $190(23.6)$ & $536(24.9)$ \\
\hline Current smoker $n(\%)$ & $414(56.9)$ & $297(48.4)$ & $385(47.8)$ & $1096(51.1)$ \\
\hline Non-smoker n (\%) & $131(17.9)$ & $142(23.1)$ & $180(22.4)$ & $453(21.1)$ \\
\hline ormer smoker $n(\%)$ & $91(12.5)$ & $107(17.4)$ & $128(15.9)$ & $26(15.1)$ \\
\hline Unknown n (\%) & $92(12.6)$ & $68(11.1)$ & $112(13.9)$ & $272(12.7)$ \\
\hline Employed n (\%) & $93(12.7)$ & $125(20.4)$ & $164(20.3)$ & $382(17.8)$ \\
\hline Unemployed n (\%) & $67(9.2)$ & $56(9.1)$ & $67(8.3)$ & $190(8.9)$ \\
\hline Retired $n(\%)$ & $315(43.3)$ & $213(34.7)$ & $276(34.3)$ & $804(37.5)$ \\
\hline Other $n(\%)$ & 252 (34.6) & $218(35.5)$ & $293(36.4)$ & $763(35.5)$ \\
\hline Most deprived $n$ (\%) & 509 (69.9) & 429 (69.9) & $552(68.6)$ & 1409 (69.4) \\
\hline Least deprived $n(\%)$ & $148(20.3)$ & $140(22.8)$ & $195(24.2)$ & $483(22.5)$ \\
\hline Rural n (\%) & $224(34.1)$ & $187(32.8)$ & 245 (32.9) & 657 (33.3) \\
\hline Urban $n(\%)$ & $433(65.9)$ & $382(67.1)$ & $501(67.1)$ & $1316(66.7)$ \\
\hline \multicolumn{5}{|l|}{ Cancer stages $n(\%)$} \\
\hline Stage I & $124(29.5)$ & $113(26.9)$ & $183(43.6)$ & $420(19.6)$ \\
\hline Stage II & $128(41.2)$ & $75(24.1)$ & $108(34.7)$ & $311(14.5)$ \\
\hline Stage III & $114(37.8)$ & $92(30.5)$ & $96(31.8)$ & $302(14.1)$ \\
\hline Stage IV & $229(30.4)$ & $228(30.3)$ & 296 (39.3) & $753(35.1)$ \\
\hline Unknown stage & $133(36.8)$ & $106(28.6)$ & $122(33.8)$ & $361(16.8)$ \\
\hline
\end{tabular}

"Due to some instances of missing data, cells may not add up to total number"

of 1000 and five women out of 1000 have a current risk of being diagnosed with OC.

\section{Multivariable analysis}

A multivariable Cox regression model assessed the risk of oral cancer adjusted for all potential confounders available in the study (Table 3).

From the Cox regression, being of older age (HR 1.6, $P<0.001$ ), being a current smoker (HR 1.3, $p=0.003$ ) and having a cancer at the base of tongue were all strongly associated with death. Conversely, being married, having a recent diagnosis of cancer (2005-2009), being less deprived and being employed were negatively associated with risk of death from oral cancer. There was a linear relationship between cancer stage and risk of death. 
Table 2 Estimated annual percent change of oral cancer incidence 1994-2009, in Ireland

\begin{tabular}{llcl}
\hline Sex & Year & $\begin{array}{c}\text { Estimated annual } \\
\text { percent change }\end{array}$ & $\begin{array}{l}95 \% \text { confidence } \\
\text { interval }\end{array}$ \\
\hline Female & $1994-2009$ & $3.2^{\mathrm{a}}$ & $1.9,4.6$ \\
Male & $1994-2001$ & $-4.8^{\mathrm{a}}$ & $-8.7,-0.7$ \\
& $2001-2009$ & 2.3 & $-0.9,5.6$ \\
Total & $1994-1999$ & $-5.2^{\mathrm{a}}$ & $-10.0,0.2$ \\
& $1999-2009$ & $2.6^{\mathrm{a}}$ & $0.8,4.3$ \\
\hline
\end{tabular}

${ }^{\text {a }}$ The estimated annual percent change (APC) is significantly different from zero at alpha $=0.05$

\section{Discussion}

Oral cancer is a significant health problem, with changing patterns in many countries including Ireland, suggesting underlying changing lifestyle factors or putative risk factor changes.

From this retrospective study of all OC cases nationally in Ireland between 1994 and 2009 we found that the increase in incidence for women was driving the population level estimate. There was a significant annual increase of $3.2 \%$ in OC among women from 1994 to 2009 similar to previous studies both in Ireland and elsewhere [28, 29].

In contrast, the trend for male OC incidence rates changed markedly between 1994 and 2009. A significant annual decrease in incidence of $4.8 \%$ between 1994 and 2001 and a non-significant increase of $2.3 \%$ was observed for the remaining years 2002-2009.

The lifetime incidence risk of OC for males was $0.7 \%$ compared to $0.5 \%$ in females between 2007 and 2009. Our estimates broadly agree with European estimates for females [6]. In 2004, the estimated lifetime risk of developing OC was $0.37 \%$ for females in European Union countries. Our analyses show that men living in Ireland are at a lower risk than their European counterparts who had a risk of $1.85 \%$ in 2004.

Specific survival rates in $\mathrm{OC}$ also varied in the study population. Smokers (HR 1.3), older patients (HR 1.6), more deprived patients and patients in advanced stages of OC cancer in which the tumour has extended beyond the organ or site of origin had significantly poorer survival rates. This result is consistent with the Neighbourhood Deprivation study in the United States [30],which reported a decreased survival rate amongst the most deprived patients between 1996 and 2009. An important factor in this context is the effect of the economic crisis in 2008. The continued decline in overall survival among the most deprived might have been compounded by the economic recession in 2008 when the Irish health care system was deeply impacted [31, 32]. However, the impact of a recession on health generally displays a significant time lag, so the whole picture will only be visible over the long term [33].

We also found that patients who developed cancers at the tongue and base of the tongue had lower survival rates than patients with other types of cancers. This might be due to asymptomatic presentation of most patients with tongue cancer leading to more advanced cancer on detection or misdiagnosis of the tumour by the attending clinician, in addition to the early nodal spread in this form of cancer [34].

Some of the observed trends may be related to underlying patterns of tobacco consumption among men and
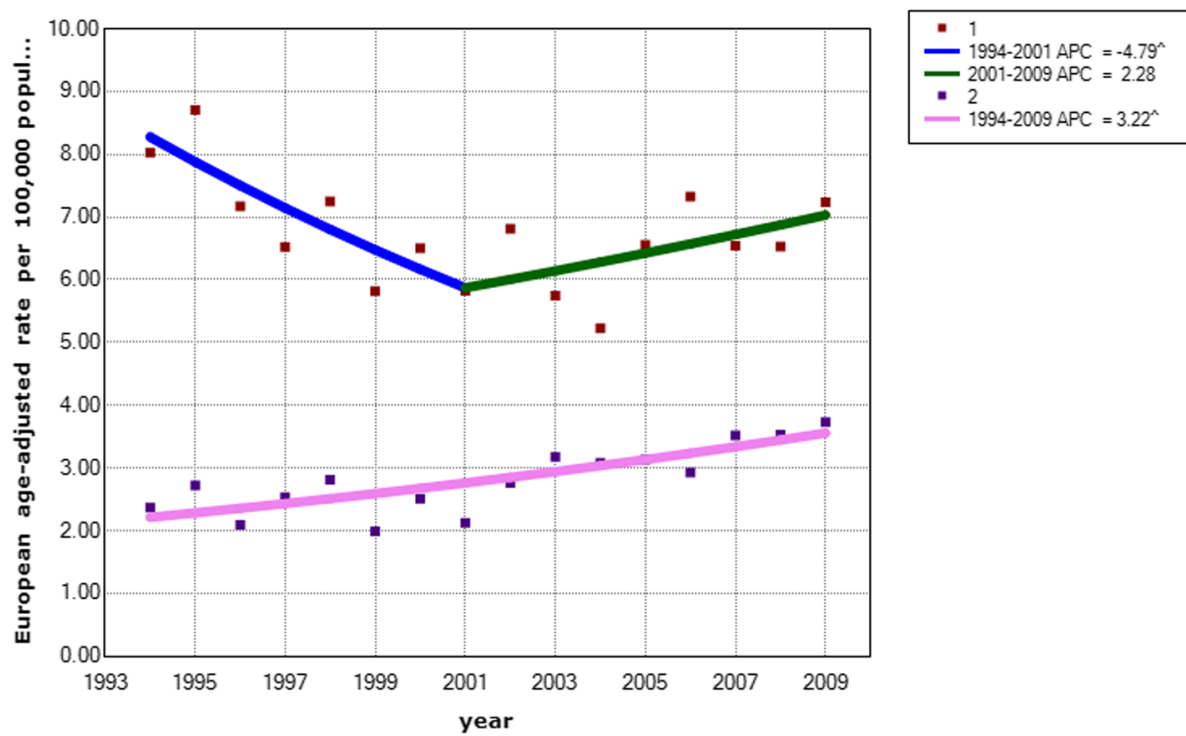

Fig. 1 Estimated annual percent in oral cancer incidence among males (top) and females (bottom), 1999-2009, Ireland: 1: 1 Jointpoint versus 2: 0 Joinpoints 
Table 3 Multivariable Cox proportional hazards regression analysis

\begin{tabular}{|c|c|c|}
\hline Variables & Hazard ratio $(95 \% \mathrm{Cl})$ & $P$-value \\
\hline \multicolumn{3}{|l|}{ Sex (reference = women) } \\
\hline Men & $1.1(0.9-1.3)$ & 0.15 \\
\hline \multicolumn{3}{|c|}{ Age (years) (reference $=30-60$ ) } \\
\hline$<30$ & $0.3(0.1-0.9)$ & 0.03 \\
\hline$>60$ & $1.6(1.4-1.9)$ & $<0.001$ \\
\hline \multicolumn{3}{|c|}{ Smoking status (reference = non-smoker) } \\
\hline Current & $1.3(1.1-1.5)$ & 0.003 \\
\hline Former smoker & $1.0(0.8-1.3)$ & 0.8 \\
\hline Unknown & $1.5(1.2-1.8)$ & 0.001 \\
\hline \multicolumn{3}{|c|}{ Marital status (reference $=$ married) } \\
\hline Divorced & $1.7(1.1-2.7)$ & 0.02 \\
\hline Single & $1.2(1.1-1.4)$ & 0.002 \\
\hline Other & $1.3(1.2-1.5)$ & $<0.001$ \\
\hline \multicolumn{3}{|c|}{ Occupation status (reference = employed) } \\
\hline Unemployed & $1.3(1.1-1.6)$ & 0.003 \\
\hline Retired & $1.5(1.3-1.9)$ & $<0.001$ \\
\hline Other & $1.1(0.9-1.4)$ & 0.18 \\
\hline \multicolumn{3}{|c|}{ Deprivation index (reference $=$ most deprived) } \\
\hline Less deprived & $0.9(0.8-0.9)$ & 0.03 \\
\hline \multicolumn{3}{|c|}{ Years of incidence (reference $=1994-1999)$} \\
\hline 2000-2004 & $0.8(0.7-0.9)$ & 0.01 \\
\hline $2005-2009$ & $0.7(0.6-0.8)$ & $<0.001$ \\
\hline \multicolumn{3}{|c|}{ Tumour site (reference = C03 Gum) } \\
\hline C01Base of the tongue & $1.3(1.1-1.7)$ & 0.01 \\
\hline C02 Tongue & $1.3(1.0-1.6)$ & 0.04 \\
\hline C04 Floor of mouth & $1.2(0.9-1.5)$ & 0.11 \\
\hline C05 Unspecified mouth & $1.1(0.5-0.8)$ & 0.62 \\
\hline C06 Palate & $1.1(0.8-1.4)$ & 0.55 \\
\hline \multicolumn{3}{|c|}{ Cancer stages $($ reference $=$ Stage $\mathrm{I})$} \\
\hline Stage II & $1.4(1.1-1.7)$ & 0.004 \\
\hline Stage III & $1.8(1.5-2.3)$ & $<0.001$ \\
\hline Stage IV & $2.8(2.3-3.3)$ & $<0.001$ \\
\hline Unknown stage & $1.7(1.4-2.1)$ & $<0.001$ \\
\hline
\end{tabular}

women over the past decades. While there has been a decrease in tobacco use across Europe over the last ten years, the consumption has decreased at a slower rate in women [35]. Regardless of the introduction of powerful measures like a workplace smoking ban in 2004, the average smoking rates in Ireland remained high at $29 \%$ in 2007 [12]. In 2006, the Health Behaviour in School Aged Children survey reported that smoking was higher amongst girls than boys for children aged 12-14 years and 15-17 years [36]. Smoking was also more common among lower social class groups in the Health Service Executive (HSE) survey 2007 [36].
The survival rate of $\mathrm{OC}$ was significantly increased amongst married patients. Similar results were reported by Schaefer et al. in a study of 9403 elderly patients with oral cavity and pharyngeal cancers in the United States [37]. Married patients have better health behaviours such as medication adherence, and are subject to encouragement by spouses to seek medical care for worrying signs [38]. Psychologically, after a cancer diagnosis, married patients display less anxiety and depression than their unmarried counterparts, as a partner can provide social support and share the emotional burden [39]. This phenomenon raises the possibility of unmarried patients being a suitable target for social support interventions that may improve survival.

In our study, the survival of $\mathrm{OC}$ decreased progressively with age. Better prognosis for the recently diagnosed $\mathrm{OC}$ rates may be associated with some time-dependent factors related to changing behaviour and/or environmental exposure such as alcohol/tobacco consumption and HPV vaccination, which unfortunately we could not control for in our analyses. The improvement in procedures of diagnosis, early referral, and treatment options of oral cancer over the years may also be contributory [40]. The Mouth Cancer Awareness Day in Ireland is a good example of a good public health intervention in this regard, albeit this was introduced after the end of our study period. The national campaign commenced in 2010 and offers free dental examinations for anyone who wishes to be examined, with the aim of early detection of oral cancer [41]. The campaign was successful; discovering an additional 22 new oral cancer cases between 2010 and 2013 [42].

Other health promotion approaches in Ireland that impact on oral health include the three-year alcohol awareness campaign "less is more" that was implemented by the Health Promotion Unit (2001-2003). The aim of this programme was to increase awareness and initiate consideration of health and societal related alcohol issues [43].

Initiatives such as these have been shown in other countries to have an impact on oral cancer incidence rates [44]. The joint effect of alcohol and smoking consumption have been shown to be strongly associated with OC $[7,8,45]$. Although we did not allow for their combined influence in our models due to an absence of data on alcohol consumption, this is a further point for research.

\section{Strengths and limitations}

We used a population-based study, using all cases of oral cancer in Ireland, to examine oral cancer incidence between 1994 and 2009. We used a comprehensive nationally representative individual-level oral cancer dataset with $>97 \%$ coverage. The advantage of employing 
joinpoint analysis, which has been consistently applied by the NCI in the United States, allows identification of significant inflexions in trend data. We have also estimated lifetime incidence risk of OC. Such an analysis might indicate underlying patterns of etiological importance that are amenable to both prevention and control of oral cancer burden in Ireland.

Robust multivariable modelling was performed to adjust for potential confounders available to the study.

However, there are study limitations. Information on important risk factors such as oral HPV status, data on oral hygiene and intake of fruit and vegetables were not available in our study. Additionally, we could not study the combined effect of alcohol consumption and smoking due to a lack of data on alcohol. These data limitations may have resulted in some residual confounding.

\section{Conclusion}

In conclusion, while the incidence of oral cancer increased significantly in both sexes between 1999 and 2009, the overall population increase appears to be driven by women (APC $3.2 \%$ per year). From our analyses, survival was better for younger and affluent groups compared to older and deprived patients. Survival rates of OC were also higher in early cases and in married couples.

Although in this study we could not control for every single risk factor, the existing evidence in combination with our contribution points to alcohol use, tobacco, dietary factors, HPV, social class in addition to time of diagnosis and age as all being important factors in the causation and prognosis of OC. Many of these factors are modifiable and thus should be emphasized as major targets for public policy aimed to positively impact the numbers of oral cancer.

\section{Abbreviations}

APC: Annual percent change; Cl: Confidence intervals; ED: Electoral division; HPV: Human papillomavirus; HR: Hazard ratios; HSE: Health service executive; ICD: International Classification of diseases; KP: Kaplan-Meier; NCRI: National Cancer Registry Ireland; OC: Oral cancer; OECD: Organisation for economic co-operation and development

\section{Acknowledgements}

Special thanks to the NCRI for providing the data. Thank you to Yousif Ali for assistance with preparing the data. This article was sponsored by the Department of Epidemiology and Public Health at University College Cork. The study sponsors were not involved in the study design, the collection of data, analysis/interpretation of the data, the writing of the manuscript or in the decision to submit the manuscript for publication.

\section{Funding}

Not applicable.

\section{Availability of data and materials}

The database on which the analysis was based is stored in the National Cancer Registry and can be made available to researchers, wishing to review the data, on request. Requests for copies of the dataset should be made to info@ncri.ie.

\section{Authors' contributions}

HA, ZK and SJS designed the study. HA, PC and ZK analysed and interpreted the data. HA, ZK and SJS prepared the manuscript. All authors (HA, SJS, ZK, PC, SD and LS) revised the article critically for important intellectual content. We confirm that the final version of the manuscript has been read and approved by all named authors.

Competing interests

The authors declare that they have no competing interests.

\section{Consent for publication}

Not applicable.

\section{Ethics approval and consent to participate}

Was obtained from the Ethics Committee of the Cork Teaching Hospitals on the 28th of April 2013 Because data from the National Cancer Registry was completely anonymized, it is classed as unrestricted/freely available and did not require ethical approval/patient consent [46].

\section{Author details}

'Department of Epidemiology and Public Health, University College Cork, Cork, Ireland. ${ }^{2}$ Department of non-communicable disease epidemiology, London School of Hygiene and Tropical Medicine, Kepple St, London WC1E 7HT, UK. ${ }^{3}$ Department of Obstetrics and Gynaecology, Cork University Maternity Hospital, Wilton, Cork, Ireland. ${ }^{4}$ National Cancer Registry, Cork Airport Business Park, Kinsale Road, Cork, Ireland. ${ }^{5}$ Institute of Health and Society, Newcastle University, The Baddiley-Clark Building, Richardson Road, Newcastle upon Tyne NE2 4AX, UK.

Received: 7 January 2016 Accepted: 5 October 2016

Published online: 20 December 2016

\section{References}

1. Cancer Research UK. Oral cancer incidence statistics. 2014. http://www. cancerresearchuk.org/health-professional/cancer-statistics/statistics-bycancer-type/oral-cancer/incidence\#heading-Five. Accessed 8 Nov 2014.

2. Hertrampf K, Wiltfang J, Katalinic A, et al. Trends in incidence, tumour sites and tumour stages of oral and pharyngeal cancer in Northern Germany. J Cancer Res Clin Oncol. 2012;138:431-7.

3. McDevitt J, Walsh P. Cancer in Ireland 1994-2013: Annual Report of the National Cancer Registry. 2015. http://www.ncri.ie/sites/ncri/files/pubs/ NCRReport_2015_final11122015.pdf. Accessed 18 Aug 2016.

4. Central Statistics Office (CSO), Ireland. Deaths occurring by sex, cause of death, age at death and year. 2014. http:/www.cso.ie/px/pxeirestat/Statire/SelectVarVal/ Define.asp?maintable=VSA08\&PLanguage=0. Accessed 19 Aug 2016.

5. Dental Health Foundation Ireland. Oral Cancer. http://www.dentalhealth.ie/ dentalhealth/causes/oralcancer.html. Accessed 4 July 2014.

6. Warnakulasuriya S. Global epidemiology of oral and oropharyngeal cancer Oral Oncol. 2009;45:309-16.

7. Ferreira Antunes JL, Toporcov TN, Biazevic MGH, et al. Joint and Independent Effects of Alcohol Drinking and Tobacco Smoking on Oral Cancer: A Large Case-control Study. PLoS One. 2013;8:e68132.

8. Petti S, Masood M, Messano GA. Alcohol is not a risk factor for oral cancer in nonsmoking, betel quid non-chewing individuals. A metaanalysis update. Ann lg Med Prev E Comunità. 2013;25(1):3-14. doi: 10.7416/ai.2013.1901. PMID: 23435775.

9. Organisation for Economic Co-operation and Development. OECD Health Statistics 2014 How does Ireland compare? 2014. http://www.oecd.org/els/ health-systems/Briefing-Note-IRELAND-2014.pdf. Accessed 21 Jan 2015.

10. Department of Health An Roinn Sláinte. Steering Group Report on a National Substance Misuse Strategy. A12/0434. 2012. http://www.drugs.ie/resourcesfiles/ reports/Steering_Group_Report_NSMS.pdf. Accessed 15 Aug 2014.

11. Hickey P, Evans DS. Smoking in Ireland 2014: Synopsis of Key Patterns. Ireland: National Tobacco Control Office Health Service Executive. 2015. http://www.hse.ie/eng/about/Who/TobaccoControl/Research/ smokinginireland2014.pdf.. Accessed 8 Oct 2015.

12. Brugha R, Tully N, Dicker P, et al. Slán 2007:Survey of Lifestyle, Attitudes and Nutrition in Ireland. Smoking Patterns in Ireland: Implications for Policy and services. Dublin: Royal College of Surgeon in Ireland, Economic and Social Research Institute University College Cork, National University of Ireland Galway; 2009. http://epubs.rcsi.ie/cgi/viewcontent.cgi?article=1011\&context= psycholrep. Accessed 17 Feb 2015. 
13. Hocking JS, Stein A, Conway EL, et al. Head and neck cancer in Australia between 1982 and 2005 show increasing incidence of potentially HPV-associated oropharyngeal cancers. Br J Cancer. 2011;104:886-91.

14. O'Connor M, Costello L, Sharp L, et al. CERVIVA-Irish Cervical Screening Research Consortium. http://www.ncri.ie/research/projects/cerviva-irishcervical-screening-research-consortium. Accessed 22 Aug 2014.

15. Keegan H, Ryan F, Malkin A, et al. Human papillomavirus prevalence and genotypes in an opportunistically screened Irish female population. Br J Biomed Sci. 2007;64:18-22.

16. Weitkunat $R$, Sanders E, Lee PN. Meta-analysis of the relation between European and American smokeless tobacco and oral cancer. BMC Public Health. 2007;7:334

17. Auluck A, Walker BB, Hislop G, et al. Population-based incidence trends of oropharyngeal and oral cavity cancers by sex among the poorest and underprivileged populations. BMC Cancer. 2014;14:316.

18. Krishna Rao SV, Mejia G, Roberts-Thomson K, et al. Epidemiology of oral cancer in Asia in the past decade-an update (2000-2012). Asian Pac J Cancer Prev. 2013;14:5567-77.

19. Sharp L. Setting the scene: Head and Neck Cancer in Ireland. http://www. conference.ie/content/SHARP\%20HNC\%20symposium\%20GalwayMay2013. pdf. Accessed 9 July 2014.

20. National Cancer Registry Ireland. Data Quality and completeness at the Irish National Cancer Registry. 2012. http://www.ncri.ie/sites/ncri/files/ pubs/DataQualityandCompletenessatthelrishNationalCancerRegistry.pdf. Accessed 30 July 2014

21. National Cancer Registry Ireland. Cancer Registration. http://www.ncri.ie/ sites/ncri/files/documents/NCR\%20Data\%20Dictionary\%20Data\%20for\%20 General\%20Queries.pdf. Accessed 30 July 2014

22. Sharp L, McDevitt J, Carsin A-E, et al. Smoking at diagnosis is an independent prognostic factor for survival in head and neck cancer: findings from a large, population-based, study. http://www.ncri.ie/sites/ncri/ files/presentations/NCIN\%20smoking\%20\%20survival\%20HNC\%202014\%20\%20with\%20QR\%20code_0.pdf. Accessed 19 Feb 2015.

23. Williams D, Teljeur C, Bennett $\mathrm{K}$, et al. Influence of material deprivation on prescribing patterns within a deprived population. Eur J Clin Pharmacol. 2003;59:559-63.

24. Carsin A-E, Sharp L, Comber H, et al. An atlas of cancer in Ireland 1994-2003. Cork: National Cancer Registry; 2009. ISBN:978-0-9554970-1-8.

25. Fleming ID, American Joint Committee on Cancer, American Cancer Society, editors. AJCC cancer staging manual. 5th ed. Philadelphia: Lippincott-Raven; 1997.

26. National Cancer Institute, Division of Cancer Control \& Population Sciences. Joinpoint Trend Analysis Software, Version 4.2.0.2. https://surveillance.cancer. gov/joinpoint/. Accessed 30 July 2014.

27. Kim HJ, Fay MP, Feuer EJ, et al. Permutation tests for joinpoint regression with applications to cancer rates. Stat Med. 2000;19:335-51.

28. Braakhuis BJM, Visser O, Leemans CR. Oral and oropharyngeal cancer in The Netherlands between 1989 and 2006: Increasing incidence, but not in young adults. Oral Oncol. 2009;45:e85-89.

29. Deady S, Comber H. Cancer Trends. No.10. Ireland: National Cancer Registry Ireland; 2011. http://www.ncri.ie/sites/ncri/files/pubs/CancerTrendsNo.10CancersoftheHeadandNeck.pdf. Accessed 22 Mar 2014.

30. Reitzel LR, Nguyen N, Zafereo ME, et al. Neighborhood deprivation and clinical outcomes among head and neck cancer patients. Health Place. 2012;18:861-8.

31. Nolan A, Barry S, Burke S, et al. The Impact of The Financial Crisis on The Health System and Health in Ireland. 2014. http://www.euro.who.int/_data/ assets/pdf_file/0011/266384/The-impact-of-the-financial-crisis-on-the-healthsystem-and-health-in-Ireland.pdf?ua=1. Accessed 21 Aug 2016.

32. Steele J, Hackett E. A Vision for Improved Oral Health in Ireland. 2013. https://www.ucc.ie/en/media/academic/dentalschool/newwebsitephotos/ documents/NisionlmprovedOralHealth.pdf. Accessed 21 Aug 2016.

33. Rodrigues $R$, Zólyomi $E$, Kalavrezou N, et al. The Impact of the Financial Crisis on Unmet Needs for Healthcare. 2013. http://www.euro.centre.org/ data/1417527848_17398.pdf. Accessed 15 Oct 2015.

34. Ionmhain U nic. A Look at Oral Cancer-Specifically Tongue Cancer, vol. 8. 2007. p. 59-63.

35. Lortet-Tieulent J, Renteria E, Sharp L, et al. Convergence of decreasing male and increasing female incidence rates in major tobacco-related cancers in Europe in 1988-2010. Eur J Cancer. 2015:51:1144-63.

36. The Health Service Executive. Tobacco Control Framework. 2010. http:// www.hse.ie/eng/about/Who/TobaccoControl/framework/framework.pdf. Accessed 2 Oct 2015.
37. Schaefer EW, Wilson MZ, Goldenberg D, et al. Effect of marriage on outcomes for elderly patients with head and neck cancer. Head Neck. 2015;37:735-42.

38. Aizer AA, Chen M-H, McCarthy EP, et al. Marital status and survival in patients with cancer. J Clin Oncol. 2013;31:3869-76.

39. Goldzweig G, Andritsch E, Hubert A, et al. Psychological distress among male patients and male spouses: what do oncologists need to know? Ann Oncol. 2010;21:877-83.

40. O'Sullivan EM. Oral and pharyngeal cancer in Ireland. Ir Med J. 2005;98:102-5.

41. Journal of The Irish Dental Association. Mouth, Head and Neck Cancer Awareness Campaign in Ireland. 2014. http://jida.ie/index.php/mouth-headand-neck-cancer-awareness-campaign-in-ireland/. Accessed 15 July 2014.

42. Shanahan C, Irish Examiner. Free dental check-up scheme reveals 22 case of mouth cancer. 2014. http://www.irishexaminer.com/ireland/free-dentalcheck-up-scheme-reveals-22-cases-of-mouth-cancer-283847.html. Accessed 15 July 2014

43. Ireland, Department of Health and Children. Strategic Force on Alcohol. Strategic task force on Alcohol: second report, September 2004. Dublin: Health Promotion Unit, Dept. of Health and Children; 2004. http://www.drugs.ie/ resourcesfiles/reports/886-STFASECONDreport.pdf. Accessed 20 Aug 2014.

44. Ariyawardana A, Warnakulasuriya S. Declining oral cancer rates in Sri Lanka: are we winning the war after being at the top of the cancer league table? Oral Dis. 2011;17:636-41.

45. Petti S, Mohd M, Scully C. Revisiting the association between alcohol drinking and oral cancer in nonsmoking and betel quid non-chewing individuals. Cancer Epidemiol. 2012;36:e1-6.

46. National Cancer Registry Ireland. Confidentiality. 2016. http://www.ncri.ie/ content/confidentiality. Accessed 12 Aug 2016.

\section{Submit your next manuscript to BioMed Central and we will help you at every step:}

- We accept pre-submission inquiries

- Our selector tool helps you to find the most relevant journal

- We provide round the clock customer support

- Convenient online submission

- Thorough peer review

- Inclusion in PubMed and all major indexing services

- Maximum visibility for your research

Submit your manuscript at www.biomedcentral.com/submit
) Biomed Central 